\title{
The response to violence
}

\section{J West Institute of Clinical Criminology, University of Cambridge}

\section{Editor's note}

In this penultimate of our selection of papers from the London Medical Group conference on 'Violence', $\mathrm{Dr}$ West examines the social conditions that determine a high incidence of homicide and personal violence. Through his experience and research he feels that politics and social organisation are perhaps more relevant than psychiatry. Statistics show that the majority of serious crimes of violence are not the work of ordinary criminals or the mentally disturbed. British murders are, in fact, mostly domestic. He supports the view that violence-prone sub groups do exist, but argues that many of the individuals involved cease to be violent after a certain period in their lives.

$\mathrm{Dr}$ West also looks briefly at the social and medical facilities available for dealing with violent individuals and stresses the importance of not responding to aggression in kind. This view is supported by examples taken from penal and hospital cases.

\section{Introduction}

The clinical and the sociological approaches to the problem of violence are very different. Working in both academic criminology and clinical psychiatry I have a foot in both camps. In this situation it is easy to see that violence in general is primarily a sociopolitical problem rather than a clinical one, but that nevertheless, psychiatric disturbance, or exposure to a criminal subculture, does sometimes contribute to the propensity of particular individuals to commit acts of personal violence. A clinical approach will not solve world problems, but it may help to alleviate the difficulties of some unusually violent individuals.

Any discussion of possible responses to individual violence must begin by taking stock of some of the wider social issues. Social anthropologists (perhaps the best known among them being the late Margaret Mead) have demonstrated many times how the level of personal aggressiveness, the readiness to resort to violence, and the relative positions of males and females on the scale of violence, vary to an extraordinary degree from one culture to another. Clearly, whatever may be the biological roots of human aggression, its practical manifestation in acts of interpersonal violence is largely determined by environmental conditioning.
In wartime, people are trained to kill and are $\varrho$ prepared to kill as a public duty without being under any exceptional individual stress. In times of $\vec{O}$ civil unrest, deaths in the course of riots, or deaths from what is called freedom fighting or terrorism $\vec{\omega}$ (depending on which side you belong to) greatly outnumber murders in the furtherance of personal $\widehat{\phi}$ gain. However, individuals who have been prepared $i$ to commit the most violent atrocities during periods $\omega$ of social upheaval will return afterwards to an $\vec{N}$ ordinary, humdrum life in which the idea of $\mathrm{O}$ violent crime never recurs. Nazi concentration camp? officers, wartime resistance fighters and Vietnam $(\overrightarrow{)}$ soldiers are among the many historical examples of $\frac{\mathbb{D}}{0}$ this kind that one might cite. The obvious lesson to $\mathbb{\mathbb { D }}$ be drawn is that much serious personal violence is $\frac{3}{0}$ the product of particular social circumstances. The $\stackrel{\mathbb{D}}{\stackrel{2}{ }}$ same individuals can be violent or non-violent $\vec{\varphi}$ according to what is expected or permitted in theor $ै$ ปे particular milieu.

\section{Personal violence and social structure}

Bearing this in mind, it becomes clear that the $\frac{\partial}{\square}$ incidence of personal violence in a community has $\stackrel{2}{\Rightarrow}$ far more to do with the social structure, and with culturally determined habits and attitudes, than with the peculiarities of individuals. For example, the striking contrast between the notoriously high homicide rates of many large American cities, compared with the low rates in countries like Denmark, cannot be due to the high psychiatric 3 . morbidity of Americans. It is much more likely to be linked with such factors as:

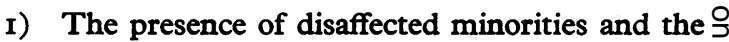

level of racial conflict in the community. (encouraged by democratic rhetoric) and the limited N possibilities of legitimate advancement available to poorly educated and disadvantaged groups.

3) Cultural support for an ideal of manliness that $\underset{\omega}{ }$ includes settling disputes with violence.

4) The tradition of weapon carrying.

5) Tolerance of heavy drinkers. respond to violence in kind.

It is a common misapprehension that serious personal violence in our own society is restricted to $\frac{}{\mathbb{D}}$ a small class of abnormal or criminal individuals. 
The fact is that a great deal of personal violence is committed by individuals we do not normally think of as criminals. Deaths caused by drunken drivers greatly outnumber deaths attributed to the crime of murder. Professor Bottoms and other criminologists have repeatedly pointed out that dangerous acts of negligence and criminal irresponsibility (including, for example, defiance of safety regulations in industry) although they cause incomparably more deaths than acts defined as wilful murder, arouse comparatively little public outcry, attract much lesser punishment and are usually excluded from discussions about violence. Part of the reason for this is that so often the persons found to be responsible are respectable and powerful members of the community who are far removed from the stereotype of the criminal classes.

In Britain, the great majority of murders are not killings in the furtherance of criminal exploits, such as bank robberies or burglaries, but are the result of interpersonal confrontations, most often in a domestic setting between members of a family or persons involved in love affairs. Child victims of homicide are usually killed by their own parents, rarely by strangers. Only a minority of these domestic murderers are criminals in a conventional sense. Far fewer of them have previous convictions for criminal offences than would be found, for example, among a sample of burglars. Many of these domestic homicides are committed under conditions of psychological stress, and are much regretted subsequently. Many such offenders commit suicide or make a serious attempt to do so, immediately after committing their crime.

Of course there are within the community groups who are more overtly violence prone than othersyoung males reared under conditions of relative social deprivation for example. Some years ago the criminologists Wolfgang and Ferracuti, in an influential book about subcultures and violence, suggested that some sections of society adopt as their norm a level of violence much higher than what would be acceptable to the rest of society. They do so as a functional response to their social situation. Where aspirations and satisfactions are frustrated by lack of legitimate opportunity, some sort of status may be attained, at least among youthful peers or in the society of street gangs, by demonstrations of physical daring and ruthlessness. It was emphasised, however, that delinquent subcultures are not without standards, even if their standards are disapproved by the wider society. Their violence is to some extent institutionalised, directed towards rival gangs, or used purposefully and in measured degree against selected victims of robbery. Among sane groups violence is never completely untrammelled by informal regulations or without some kind of rationalisation.

In some London research with which I have been concerned we were struck by the frequent involve- ment of urban working class youths in fights in which weapons are often used (eg knives, combs, $\unrhd$ bottles). Recidivist delinquents were particularly prevalent among the minority who reported frequent and serious fighting. Belief in the existence of violence-prone criminal groups is not without some foundation, although the threat such youths pose to each other is generally much greater than that to innocent outsiders. Moreover, follow up work shows that a few years later these same youths have largely abandoned their fighting habits.

\section{Violence and social organisation}

Viewed in its widest context human violence is a global problem of social organisation. The incidence of violence is affected by the state of international relations, the effectiveness of socio-economic or systems in providing for the needs of all groups within the community, the competence and power of $N$ ruling authorities to control and suppress rebellious and discontented individuals, the existence of educational and cultural influences supportive of or $c s$ antagonistic towards the use of violence, and the $\mathbb{D}$ availability of alternatives to violence for securing individual and community goals. $A$ just and equitable society extending over the whole world, permitting freedom of expression without need to $\vec{\varphi}$ resort to violence, might go a long way towards cे reducing the problem, but apparently insuperables difficulties and conflicts of interest stand in the ways Certainly no single panacea would suffice to achieve this millenium.

The responses to violence open to the medical and related professions are limited, and likely to apply to special minorities, and hence to make a relatively small contribution, Nevertheless, a few suggestions may be worth considering.

Since domestic violence so often occurs in a context of family conflict and stress, services to which individuals can turn for guidance at times of crisis might help to prevent some of these outbursts. We already have constructive examples in the shape of the alert system operated by the social services in connection with families in which infants are believed to be at risk of battering, and in the shelters for wives in fear of assault from their husbands. $\frac{7}{0}$ More could be done along these lines by way of walk-in clinics which, like the Samaritans, would N cater for persons needing immediate attention in $N$ crisis situations.

The consumption of alcohol has increased, $\omega$ especially among the young. Educative propaganda, and a more vigorous application of social restraints, $\stackrel{\varrho}{=}$ such as taxation, the ban on sale to minors and the $\mathscr{D}$ laws against driving after drinking, might reduce the large number of incidents of criminal violence that occur after heavy drinking. Facilities for the $\overrightarrow{\mathbb{D}}$ detoxification and subsequent rehabilitation of $\frac{?}{\mathbb{P}}$ chronic drunks, especially those who have been 
arrested for assault, would reach a minority who are particularly violence prone.

Although the connection between mental illness and potential for violence is often much exaggerated, undoubtedly there is a minority of violence prone mental patients. They include some who are frankly deluded and psychotic, some who are impulsive and irritable as a result of brain damage, but many others who have no more precise diagnosis than personality disorder, although they may range from dangerously aggressive psychopaths to frustrated social inadequates. The modern mental hospitals, in their pursuit of 'open door' policies and minimal use of coercion, no longer provide suitable asylum for such individuals. Patients who cannot or will not respond are forthwith discharged into the community. Hostels, supervised homes and sheltered employment or occupation, which are supposedly provided by the community social services, are all in disgracefully short supply. The result is that mental patients, lacking appropriate supervision and care, are brought before the courts for thefts and assaults. The hospitals decline to take them back, so they get sent into temporary cold storage in prison, where the authorities complain of the influx of mental cases who ought to be looked after elsewhere. The intolerance of hospital staffs towards difficult patients, and the inadequacy of community care, which allows mental patients to drift into the hands of the law, makes a definite contribution to the incidence of violence by psychiatric patients. The Butler Committee, which examined the provisions for mentally abnormal offenders, sensibly recommended the setting up of secure mental hospital units in each region, to relieve pressure on the Special Security Hospitals, such as the grossly overcrowded Broadmoor Hospital, and to divert mental cases from the prisons. The medical response has been far from welcoming, and the recommendations have still to be properly implemented. No one likes being lumbered with patients who are ungrateful, difficult to control and potentially disruptive, but the demarcation disputes going on between the penal system and the health service are both undignified and unhelpful, especially as this is an area in which the medical profession could make a significant contribution.

\section{Coping with the aggressive individual}

This brings me to a more general point, how best to cope with aggressive individuals. In the bad old days of the mental hospital service control was maintained with straitjackets, padded cells and above all by hefty male attendants. Even before the introduction of modern medications for quelling psychotic agitation, considerable success in diminishing the incidence of violence was achieved by introducing the softer touch of female nurses into the refractory wards, and by relaxing some of the oppressive institutional rules and restrains. The old $\stackrel{\circ}{\circ}$ system hampered natural human contacts with the staff, allowed no outlet for free discussion of irritations and grievances and, by keeping patients? at the bottom of an unpleasant pecking order, $\overrightarrow{\vec{F}}$ stimulated rather than soothed their aggression.

An authoritarian approach to aggressiveness, although sometimes necessary and inevitable, can $\overline{\bar{m}}$ serve to provoke avoidable violence. In the US mental patients guilty of criminal offences were apt to be detained in large, impersonal and heavilyw authoritarian state hospitals for indefinitely long $\vec{O}$ periods because they were perceived by the staff as far too violent to be safe to release. The situation $\bar{\rho}$ changed when the courts, beginning with the famous Baxtrom case, began to declare such ${ }_{\widehat{\Phi}}$ indefinite detention legally unjustified. Manyir supposedly violent patients were suddenly released $\omega$ as a result of these decisions, but without any of the ${ }_{\infty}^{N}$ disastrous consequences that had been foretold by응 the more conservative institutional psychiatrists. $A_{-}$ relaxed approach to aggression often pays off.

This lesson can be applied with advantage by $\frac{\mathbb{D}}{0}$ police and prison officers as well as by hospital $\mathbb{D}$ staffs. Some years ago the psychologist Hans 0 Toch carried out an investigation in which he $\frac{\mathbb{S}}{?}$ showed that certain policemen, by their uncom- $\overrightarrow{0}$ promising responses and readiness to anticipace $c$ violence, actually suffered far more assaults tha their less rigid colleagues. There is a smalio experimental unit at Barlinnie Prison in Scotland where violent men serving long terms of imprisonment are kept in what amounts to a miniature $\frac{\bar{\phi}}{8}$ therapeutic community run by group discussion $\stackrel{\varrho}{\Rightarrow}$ more than by the automatic application of rigid rules. The experiment has demonstrated that some aggressive criminals who have been dangerously disruptive to the ordinary, authoritatian prison regime, will calm down and cooperate in a different kind of setting. In contrast, in the days when corporal $\stackrel{\square}{\circ}$ punishment was freely applied in the penal system, 3 especially for offences of overt aggression, experience showed that, whatever might be the deterrent effect upon potential offenders, those who 0 actually experienced these legalised assaults had an increased likelihood of involvement in further $\frac{7}{0}$ violence.

I mentioned earlier the existence of groups of $N$ violence-prone delinquent youths, most of whom N fortunately outgrow their physical aggressiveness as $N$ they get a little older. Is it better to wait for this to happen or to try to speed up the process by taking firm penal action through more arrests and prosecu- $\stackrel{O}{=}$ tions ? In our research we found that the delinquent $\stackrel{D}{\rightarrow}$ habits and aggressive attitudes of young offenders increased significantly after a first conviction, whereas others of the same age who were equally $\underset{\mathbb{D}}{\mathbb{D}}$ badly behaved, but had escaped conviction, $\frac{\Omega}{\overparen{ }}$ steadily improved.

- 


\section{Sexual violence}

Let me close by mentioning the problem of sexual violence, and by this I mean truly violent incidents, not the commonplace crimes of rape, most of which do not involve any physical injury, and many of which arise in the course of normal social interactions between couples known to each other. I had occasion recently to study a group of seriously violent sex offenders who had committed repeated and brutal attacks on total strangers. They were serving long sentences of imprisonment in a Canadian penitentiary. They had been selected as suitable cases for psychiatric intervention and were undergoing intensive psychological study and group psychotherapy led by a skilled woman therapist. The most striking point about these men was their extraordinary ambivalance towards women. The harboured feelings of burning resentment for all the frustrations and put downs which they felt (often quite unrealistically) that they had suffered at the hands of women. Their crimes were at least as much acts of symbolic revenge as outlets for lust. As they themselves gained insight into their motives their attitudes changed and everyone who knew them thought they had become less dangerous. None of the men had passed through that particular treatment programme has re-offended sexually so far, although all of them were serious and mostly repetitive offenders. To my mind this kind of approach, specialised and selective as it has to be, is a more efficient response than long detention under conditions that leave the offender bitter and still more dangerous on release.

\section{Conclusion}

As I said at the outset no single panacea will solve all problems. However, for those who must try to cope with aggressive violence-prone, individuals, whether they are labelled criminals or psychiatric cases, avoidance of the automatic tendency to respond in kind is perhaps the most useful single piece of advice that one can give. 